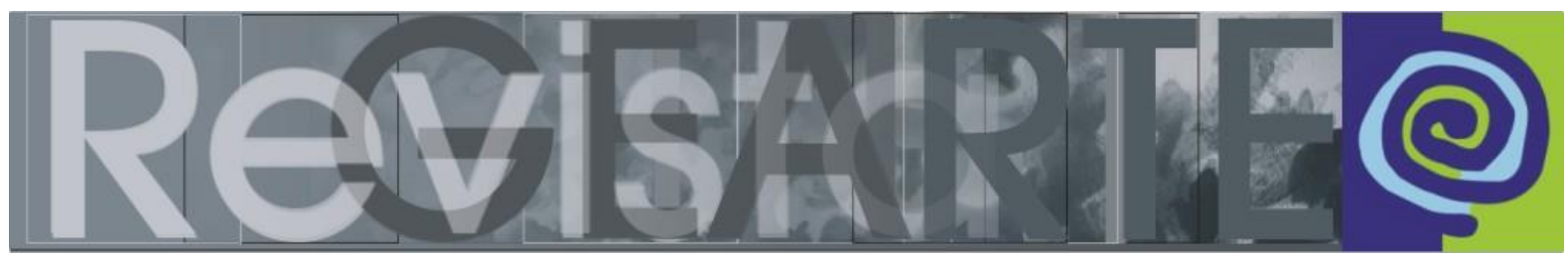

e-ISSN 2357-9854

\title{
Discursos de autolegitimação do ensino da arte: alguns problemas histórico-conceituais
}

\author{
Cayo Honorato (Universidade de Brasília — UnB, Brasília/DF, Brasil)
}

\begin{abstract}
RESUMO - Discursos de autolegitimação do ensino da arte: alguns problemas históricoconceituais - Por meio de uma análise dos argumentos que foram mobilizados pelo ensino da arte após a publicação da Medida Provisória n. 746, em setembro de 2016, assim como dos argumentos que têm sido mobilizados pela literatura da área desde os anos 1970, com base principalmente em textos e entrevistas de Ana Mae Barbosa, este artigo propõe uma discussão (histórica e reflexiva) sobre o modo como temos defendido a importância do ensino das artes na educação.
\end{abstract}

PALAVRAS-CHAVE

Ensino da Arte. Autolegitimação. Políticas Educacionais.

ABSTRACT - Discourses of self-legitimation of art education: some historical-conceptual problems - By means of an analysis of the arguments that were mobilized by the art education after the edition of the Medida Provisória n. 746, by the Brazilian government, in September 2016, as well as of the arguments that have been mobilized by the literature of the area since 1970, considering especially books and interviews by Ana Mae Barbosa, this article proposes a (historical and reflexive) discussion about the way we have defended the importance of the art teaching within education.

KEYWORDS

Art Education. Self-Legitimation. Educational Policies.

Em 22 de setembro de 2016, o governo brasileiro editou uma Medida Provisória (MP), retirando a obrigatoriedade do ensino da arte no Ensino Médio. A reação da área foi imediata: a questão virou pauta de encontros, notas de repúdio foram publicadas, parlamentares foram acionados. Meses depois, em 16 de fevereiro de 2017, a consolidação da MP pela Lei no 13.415 pareceu restabelecer aquela condição, porém, nos termos de um "componente curricular obrigatório da educação básica" e não mais "nos diversos níveis da educação básica", como havia sido consignado pela Lei no 9.394 de 1996 e mantido pela Lei no 12.287 de 2010. Com isso, teme-se que a oferta desse componente curricular em apenas um dos níveis da educação básica seja tomada como suficiente. Contudo, mais do que assinalar essa (perversa) ambiguidade, para então produzir uma nova série de contra-argumentos, parece-me oportuno revisar o modo como temos, enquanto área afetada, argumentado em favor 
das artes na educaçãoํ. Trata-se de uma tarefa, a um só tempo, histórica e reflexiva, que também mereceria ser desdobrada.

Essa é uma questão recorrente para a área, talvez até mesmo um elemento constitutivo da sua identidade. Observe-se que, mesmo diante de conquistas, a área é convidada a se justificar. É o que exemplifica a entrevista intitulada $A$ importância do ensino das artes na escola, concedida por Ana Mae Barbosa (2016a) após a promulgação da lei que definiu "as artes visuais, a dança, a música e o teatro" como linguagens constitutivas do ensino da arte (Lei nำ13.278 de 2016, Art. 26 § 6으). No livro A imagem no ensino da arte (originalmente publicado em 1991), a autora confirma a recorrência desse convite: "Sempre me encomendam textos ou palestras com o título 'A importância da Arte na Escola'” (BARBOSA, 2004, p. 27). Já em meados dos anos 1970 ela registra essa demanda, sugerindo uma explicação: "É, portanto, entendível [em razão dos preconceitos contra a Arte] que os estudos sobre ArteEducação estejam sempre insistindo em provar a importância da Arte na educação, o que é ainda pouco evidente para muitos" (BARBOSA, 1975, p. 39). Mas o fenômeno não é exclusivamente brasileiro, como observa Rubén Gaztambide-Fernández, educador porto-riquenho radicado no Canadá, referindo-se à tradição norteamericana:

A literatura acadêmica sobre o ensino de arte está cheia principalmente de argumentos de defesa. [...] Richard Siegesmund (1998) declara que a necessidade constante de reafirmar o valor das artes é o "problema peculiar" dos educadores em arte, "que devem lutar para manter a presença de sua disciplina no currículo". (GAZTAMBIDE-FERNÁNDEZ, 2013, p. 212-213, tradução minha) $)^{2}$

De acordo com essas posições, o educador em arte é alguém que precisa constantemente se justificar em face de preconceitos e outras objeções, que não cessam de nos ameaçar e provocar. Embora as ameaças nos desreconheçam, tomálas pelo avesso (como provocações) pode nos convidar a uma reflexão sobre alguns de nossos hábitos políticos e discursivos. Certamente, assim como nossa

1 Por certo, a questão sobre a importância das artes na educação não deve estar separada da questão sobre a importância das artes para o indivíduo e a sociedade, como bem lembra Ana Mae Barbosa (1975, p. 90). Porém, pensá-la em relação à educação implica a discussão de uma institucionalidade particular, relativa às perspectivas teórico-metodológicas do ensino da arte no Brasil.

2 Todas as citações de referências em língua estrangeira feitas neste artigo têm tradução minha. 
"identidade", aquela ambiguidade não é nova. No início dos anos 2000, apesar da obrigatoriedade recém estabelecida pela LDB "nos diversos níveis da educação básica", Ana Mae Barbosa já denunciava:

A aprendizagem da Arte é obrigatória pela LDB no Ensino Fundamental e no Ensino Médio. Contudo, algumas escolas estão incluindo a Arte apenas numa das séries de cada um desses níveis porque a LDB não explicitou que esse ensino é obrigatório em todas as séries. [...] No Brasil, como vemos, nem a mera obrigatoriedade nem o reconhecimento da necessidade são suficientes para garantir a existência da Arte no currículo. (BARBOSA, 2002, p. 13-14, grifo meu)

Sendo assim, a luta pela manutenção da legislação anterior (de 1996 ou 2010), em que pese a importância da prerrogativa legal, pode assumir desde o início certa ineficácia. Talvez fosse o caso de reivindicar "em todas as séries [ou anos]", não só "nos diversos níveis". Ou ainda, visando uma organização da luta: agir com inteligência, mobilizar apoiadores, dosar energias, não municiar inimigos. Por exemplo, em tempos de fake news, compartilhar que "logo seremos carreira extinta"3, embarcando em correntes alarmistas que ignoram o texto de 2017 (Lei no 13.415), pode corroborar uma perda de foco ou mesmo a capitulação diante do que importa disputar. Em meio a tanto, não seria menos importante perguntar: Que argumentos temos mobilizado? O que temos defendido ou reivindicado? De que forma temos argumentado?

\section{A vigência da formação integral}

Como disse, a reação da área à edição da MP foi imediata. No dia seguinte, a Diretoria da Federação de Arte-Educadores do Brasil (FAEB) publicou uma nota em que defendia uma "formação humana integral - comum a todos os estudantes da educação básica brasileira", argumentando que "a formação técnica [que a reforma estaria priorizando] não prescinde da criação, da reflexão, da criticidade, da criatividade e da reflexividade que a arte pode proporcionar na interdisciplinaridade curricular" (FAEB, 2016). Do mesmo modo, o Fórum de Coordenadores dos Cursos

3 A frase faz parte de mensagem compartilhada via WhatsApp e outras redes sociais nos dias que antecederam a votação pelo CNE do relatório final da BNCC relativa ao Ensino Fundamental, em 06 e 07 de dezembro de 2017. 
de Graduação em Artes Visuais (FCG), quatro dias depois, publicou nota de repúdio em que afirmava:

\begin{abstract}
Entendemos que a arte deve compor a formação integral dos estudantes e deve permanecer obrigatória no Ensino Médio por sua contribuição específica para a formação do pensamento autônomo e crítico, a valorização das culturas e do patrimônio histórico-cultural brasileiro e o exercício estético, cuja centralidade da imagem nos tempos atuais requer a compreensão de seus códigos. (FCG, 2016)
\end{abstract}

Chama a atenção que ambos recorram à formação integral, como algo de que a arte devesse necessariamente participar. Situam-se dessa forma em relação a outras disciplinas, mas sem deixar de registrar a especificidade e/ou complementaridade dessa matéria. $O$ argumento parece ter repercutido. No ano seguinte, a Carta de Campo Grande da FAEB se refere à posição de alguns parlamentares, dentre eles, o então deputado André Figueiredo (PDT/CE), para quem "[...] é inconcebível pensar na formação integral do aluno sem as citadas disciplinas [educação física, arte, sociologia e filosofia]", e o então senador Pedro Chaves (PSC/MS), relator da reforma do Ensino Médio, para quem a retomada da obrigatoriedade do ensino de educação física e arte é justificável, por acreditar que "a formação integral do ser humano exige o atendimento de várias dimensões, dentre as quais a corporeidade, o movimento e a fruição não podem ser desconsiderados" (cf. FAEB, 2017).

Todavia, dois ou três pontos precisariam ser considerados: (1) que a formação integral não se confunde com o tempo integral, este sim reforçado pela MP com a ampliação (progressiva) da carga horária do Ensino Médio (de 800 para 1400 horas anuais); (2) que a formação integral foi incluída na LDB pela MP, estando consignada no atual $\S 7^{\circ}$ no Art. 35-A, onde se lê: "Os currículos do ensino médio deverão considerar a formação integral do aluno, de maneira a adotar um trabalho voltado para a construção de seu projeto de vida e para sua formação nos aspectos físicos, cognitivos e socioemocionais"; (3) que a ideia de formação integral, ao menos de uma perspectiva pós-moderna, marcada pela "dissolução dos pontos de vista", pode ter se tornado inviável. Segundo Celso Favaretto (2004, p. 44),

Embora sabendo os educadores que a ação pedagógica procede hoje da interseção de teorias e pesquisas de procedência diversa, que é inadequado 
tratar as novas tecnologias [...] apenas como novos meios de comunicação - pois seus procedimentos são determinantes para o processo de dissolução dos pontos de vista centralizadores da consciência, sensibilidade, afetos e linguagem -, parece que eles, os educadores, ainda sonham com uma espécie de unidade em que 'todos os elementos da vida cotidiana e do pensamento encontrariam um lugar como em um todo orgânico' (Lyotard), tendo em vista a formação integral dos educandos.

Embora se refira a um sentido específico de formação integral, que não se reduz a uma soma de competências ou habilidades, mas sonha com um todo orgânico, Favaretto nos sugere uma reflexão quanto à vigência de nossos próprios argumentos. Pode-se objetar que seria inoportuno questionar o que está sendo mobilizado pela área. Todavia, um dos efeitos da "doutrina do choque" a que estamos sendo submetidos (BARROCAL, 2017) é, justamente, desorientar-nos das discussões que julgamos importante fazer; impedir-nos que as façamos com a devida disposição. Certamente, não seria o caso nos questionarmos diante de interlocutores "externos" (parlamentares, detratores, etc.). Mas seria o caso evitá-lo internamente, entre profissionais e pesquisadores da área; discussões que nos confrontam com nossas próprias certezas?

\section{Contradições da obrigatoriedade}

Outra discussão que podemos fazer diz respeito ao próprio estatuto da obrigatoriedade em nossa tradição argumentativa. Em diferentes momentos (1996 e 1971), a obrigatoriedade é tanto o objeto de uma luta, quanto aquilo que deve ser ressalvado. Segundo Ana Mae Barbosa (2008, p. 19), "A luta mais importante [da Arte/Educação] se deu em prol da continuação da obrigatoriedade da arte na Lei de Diretrizes e Bases Nacionais Darcy Ribeiro, que começou [por volta de 1988] antes de que se tornasse a LDBN do Darcy". A posição reforça a ideia de que essa luta constitui um elemento identitário da área. Contudo, ao avaliar a LDB de 1971, sua posição a respeito da obrigatoriedade assume outra perspectiva:

\footnotetext{
Hoje pode parecer estranho que uma ditadura tenha tornado obrigatório o ensino da arte nas escolas públicas. Contudo, tratava-se de um mascaramento humanístico para uma lei extremamente tecnicista, a 5692, que pretendia profissionalizar os jovens na Escola Média. (BARBOSA, 2008: 10)
}

Certamente, pode parecer estranho que aquilo pelo que estamos lutando tenha sido obra da ditadura. Mas o texto resolve essa estranheza, sugerindo haver se tratado 
de uma medida ambivalente, de uma "obrigatoriedade" com segundas intenções. No entanto, outras questões podem ser levantadas a partir dessa leitura: Essa obrigatoriedade não terá sido (também ela) resultado de uma luta, ainda que posteriormente assimilada pelo governo? Por que a ditadura teria se preocupado em "mascarar humanisticamente" sua vontade tecnicista? Quais são as nossas garantias de que a obrigatoriedade atual também não esteja servindo de máscara? Qual terá sido efetivamente o papel da Educação Artística na escola profissionalizante que a ditadura quis fomentar?

Tais questões indicam a necessidade de se registrar com mais precisão as ambivalências da LDB de 1971, mas também aquilo pelo que lutamos hoje. Do mesmo modo, as demandas urgentes também podem ser vistas como problemas históricos. Em 2016, por exemplo, o argumento se torna explicitamente contraditório. Ele atribui à obrigatoriedade um caráter nocivo, ao mesmo tempo em que insiste na sua defesa:

\begin{abstract}
A ditadura de 1964 comprometeu a qualidade quando tornou a arte obrigatória no ensino de Primeiro e Segundo Grau, com o objetivo de mascarar humanisticamente o excessivo tecnologismo da reforma educacional que pretendia profissionalizar os adolescentes. [...] Agora a coisa é pior. Estão retirando do Ensino Médio a obrigatoriedade do ensino das artes (BARBOSA, 2016b).
\end{abstract}

Por certo, ao mesmo tempo em que a consolidação da MP em 2017 parece restabelecer a obrigatoriedade do ensino de arte (como componente curricular), ela introduz de forma temerária que "A Base Nacional Comum Curricular referente ao ensino médio incluirá obrigatoriamente estudos e práticas de educação física, arte, sociologia e filosofia" (Art. 35-A $\S 2^{\circ}$ da LDB, grifo meu). A expressão "estudos e práticas" nos remete à distinção entre "disciplinas" e "áreas de estudo e atividades" feita em 1971, que parece ter relegado a Educação Artística a um segundo plano, sendo por isso motivo de apreensão. É o que se lê nos PCNs produzidos a partir da LDB de 1996: "Em 1971, pela Lei de Diretrizes e Bases da Educação Nacional, a arte é incluída no currículo escolar com o título de Educação Artística, mas é considerada ‘atividade educativa' e não disciplina” (BRASIL, 1997, p. 24).

No entanto, mais do que determinada pela letra da LDB, essa distinção parece ter sido provocada por uma acomodação desfavorável da Educação Artística no 
currículo, assim como por um contexto de formação precária do professorado. Sendo assim, aquela apreensão se esquece de que o estatuto do ensino da arte no currículo está sob disputa, ainda que com desvantagens para a área; que o currículo, seja ele qual for, deve ser tomado como campo de batalha. Além disso, a própria obrigatoriedade (em associação à ideia de disciplina), na medida em que implica certa institucionalização das práticas artísticas, pode parecer intrinsecamente contraditória. É o que sugere Irene Tourinho (2002, p. 32), "Se a institucionalização de um campo de conhecimento oferece riscos à experimentação, abrangência e profundidade de temas e experiências, no caso da Arte esta institucionalização teve também suas implicações".

\section{Algumas repetições, um dilema}

Em todo caso, para além dessas contradições, podemos observar que alguns argumentos se repetem, seja como iterações nas quais ainda é preciso insistir, seja como hábitos nos quais se deixou de pensar. Algo do que tem sido mobilizado agora para defender o ensino de arte data de 60 anos atrás. É o que atesta Ana Mae Barbosa em 2016, ao ressaltar a importância da experiência com as artes, particularmente para os adolescentes, em meio a mudanças de muitos tipos (hormonais, corporais, de modo de pensar e sentir): "A linguagem presentacional das artes articula a cognição através da integração do pensamento racional, afetivo e emocional numa escola, à qual só interessa a linguagem discursiva e científica das evidências" (BARBOSA, 2016b). Trata-se de um argumento de tipo "essencialista" - ao que retornarei mais adiante -, baseado num texto de Susanne Langer, com o título The Cultural Importance of the Arts (1958) - ao qual Ana Mae recorre desde os anos 1970 (cf. BARBOSA, 1984, p. 61).

Para Langer (1966), a linguagem discursiva é inadequada à transmissão da experiência subjetiva, do que ela chama de "vida íntima dos sentimentos e das emoções". Noutros termos, "A natureza real do sentimento é algo que a linguagem como tal - enquanto simbolismo discursivo - não pode oferecer". Essa experiência, segundo ela, encontra sua expressão formal nas artes: "Em certo sentido, pode-se dizer que um trabalho de arte simboliza o sentimento, eis que ele formula nossas ideias de uma experiência interior, assim como o discurso formula nossas ideias sobre coisas e fatos do mundo exterior". Todavia, convém sublinhar que, diferentemente de 
um símbolo como tal, um trabalho de arte não simboliza alguma coisa para além de si mesmo; o sentimento que ele expressa se encontra de certo modo embutido na própria forma expressiva - sendo essa a sua especificidade. Nesse sentido, "um trabalho de arte apresenta algo como uma visão direta da vitalidade, da emoção, da realidade subjetiva" (grifo meu).

Nota-se que os argumentos de Langer parecem circunscritos por uma concepção "psicológica" (ou romântica) da arte, seja como objetificação do sentimento, seja como subjetificação da natureza e do mundo. Em todo caso, é razoável conceber que o pensamento discursivo não alcança todas as dimensões da subjetividade humana. Do mesmo modo - se pesa uma desconfiança histórica sobre a imaginação, a ponto de fazer com que a escola adote aquele pensamento de forma excludente -, é razoável perguntar quais dimensões humanas estariam sendo sacrificadas nesse processo. Mas os argumentos de Langer - a par da dicotomia entre verbal e visual - parecem baseados numa analogia entre o "padrão intrincado" do sentimento e as "formas dinâmicas" da arte, sem demonstrar de quais formas a arte tem conseguido manifestar aquele padrão - o que termina redundando numa defesa retórica da precedência da imaginação: "A imaginação é provavelmente a característica mais antiga do que é tipicamente humano - mais antiga do que a razão discursiva; é provavelmente a fonte comum do sonho, da razão, da religião e de toda observação geral verdadeira" (LANGER, 1966, p. 10).

Em suma, na medida em que avalizados por um além ou aquém da linguagem discursiva, os argumentos essencialistas têm dificuldade para se apresentar "textualmente". Não por acaso, desde os anos 1970, Ana Mae Barbosa recorre a argumentos mais pragmáticos para defender a linguagem presentacional da arte: "Essa dicotomia [entre domínio afetivo e cognitivo] na ação educativa leva ao desequilíbrio no desenvolvimento interno, e tem sido apontada frequentemente como um perigo para a saúde mental" (BARBOSA, 1975, p. 59). Além disso, ao favorecer o desenvolvimento da criatividade, aquela integração teria repercussões econômicoprodutivas: "[...] os conteúdos afetivos da expressão artística ampliam as forças de introjeção no produto [gerando novos produtos], tornando possível um feedback mais 
afetivo" (BARBOSA, 1975, p. 60). Contudo, tal recurso - que também pode ser observado em: Barbosa (2002, p. 17-18 e 2008, p. 16) - não se faz sem ressalvas:

[...] sabemos que, pelos processos afetivos que mobiliza, a Arte pode ser um poderoso auxiliar para o enriquecimento do processo de aprendizagem dos demais conteúdos cognitivos escolares [...]. Entretanto, ligar parasiticamente a Arte a outros assuntos [...] é atitude metodológica que vem se generalizando, sendo defendida pelos próprios professores de Arte, inclusive para justificar a importância da Arte na escola, o que a torna paradoxalmente disciplina secundária [...]. (BARBOSA, 1975, p. 90).

Nesse contexto, persiste um esquema argumentativo básico, cujo caráter "paradoxal" parece ainda pouco observado: De um lado, uma visão intrínseca ou essencialista da arte - atenta a suas especificidades, para a qual a arte se justifica em si mesma, nos termos de uma experiência estética por exemplo - atribui a essa atividade um papel primordial, mas tende a convencer principalmente um público interno. De outro, uma visão instrumental ou contextualista - disposta a pensar tais especificidades em meio a outras demandas, para a qual os efeitos da arte (em termos de resultados não artísticos, como o rendimento escolar em geral) poderiam ser comprovados - Ihe atribui um papel secundário, que no entanto parece alcançar um público mais amplo (cf. BARBOSA, 1984, p. 53 et seq.; GAZTAMBIDE-FERNÁNDEZ, 2013, p. 212). Em suma, que visão adotar? Quem desejamos convencer e como? É o que pergunta Ana Mae (2016b), ao considerar outros públicos: "Que podemos fazer para que os 'homens do poder' nos ouçam?" Mas vemos que ambas visões são insuficientes. Assim, mais do que insistir numa rivalidade (histórico-conceitual) entre ambas, talvez fosse o caso buscarmos certa composição entre elas, visando uma argumentação igualmente pública e "específica".

Ainda nesse contexto, ao menos duas questões parecem pouco observadas. A primeira é, justamente, uma questão de endereçamento: A quem dirigimos tais argumentos? E se eles alcançam somente quem já se encontra predisposto a ser convencido? A segunda questão - que se conjuga com a primeira - passa pela "verificação" dos argumentos. Novamente, a questão pode parecer inoportuna, já que a verificação - ou "linguagem das evidências" - parece representar a demanda de um cientificismo refratário às artes. O problema é que os atores internos à área, em sua predisposição para defendê-la, tendem a prescindir da verificação, dispensando não 
só a necessidade de interlocução com os "cientistas", como a própria reflexão sobre os pressupostos de sua argumentação; mobilizando argumentos de maneira simplesmente declarativa - como se seus enunciados denotativos pudessem operar enquanto performativos (cf. LYOTARD, 2000, p. 15 et seq.). Afinal, o que sabemos sobre o modo como o pensamento racional e o emocional se integram por meio das artes, por exemplo? A importância da Arte será evidente para os próprios educadores?

\section{A "retórica dos efeitos"}

Ocorre que tanto os argumentos intrínsecos quanto os instrumentais, segundo Gaztambide-Fernández (2013), estariam submetidos a uma mesma "retórica dos efeitos": "[...] a maioria dos argumentos toma uma única forma - a de que as artes fazem. [...] se elas refinam, cultivam, transformam, aprimoram, impactam ou mesmo ensinam, o que importa é que elas fazem" (grifo do autor). Noutros termos, aqueles argumentos podem até discordar sobre os efeitos que devem ser enfatizados, mas não que as artes produzem efeitos. Para tanto, eles combinam dois fatores: (1) uma concepção substancialista das artes, como uma coisa em si capaz de influenciar inúmeros resultados educacionais e experiências individuais, e (2) um modelo de educação baseado na causalidade, que busca medir nos indivíduos os efeitos de algum tipo de encontro com as artes. O problema dessa retórica, segundo o autor, é que ela impede a discussão sobre as próprias concepções de artes (vigentes e alternativas), ou ainda, que concepções de artes mais comprometidas com a democracia cultural - definidas segundo ele por "práticas e processos de criatividade simbólica", ou ainda, pelas "experiências efetivas que as pessoas têm com processos de produção cultural" - se tornem referenciais.

Em vez de uma substância, o conceito das artes, segundo GaztambideFernández, deve ser pensado como um "constructo discursivo", que reflete e reproduz as valorações de um contexto sociocultural particular, mas que nem sempre considera a ocorrência (por vezes imprevisível) de encontros com as artes (e outros processos) em "sistemas abertos do mundo social". Com isso, ele não pretende invalidar a crença no poder transformador das artes, mas sim ressaltar que "isolar e aplicar inputs artísticos", para depois "observar e mensurar outputs educacionais", continua sendo um desafio. Para que a demonstração de certos efeitos tenha credibilidade, as artes 
terminam sendo reduzidas a determinadas variáveis, em correspondência a resultados previamente desejados. Em suma, as exigências feitas por essa retórica ignoram as interações cotidianas em contextos concretos, entre os processos simbólicos e seus múltiplos agentes. Ou ainda, ignoram o modo como as concepções humanistas e liberais das artes - com as quais se solidarizam - são centrais em muitos processos de exclusão e desigualdade social.

Assim, em vez de promover as artes como um tipo de panaceia, GaztambideFernández propõe que busquemos entender a cultura de maneira "aprofundada", enfatizando as interações reais entre pessoas reais, em contextos e circunstâncias atuais, nos quais certas experiências simbólicas são compartilhadas. Afinal, não são as artes por elas mesmas que provocam tais experiências, mas sim o engajamento cotidiano das pessoas em práticas culturais de vários tipos - o que inclusive pode resultar em experiências não necessariamente positivas, cuja complexidade, portanto, deve ser considerada. Nesse sentido, seria preciso levar em conta o modo como as pessoas interagem, como se desdobram essas interações e como sentidos são negociados nesses processos, sob condições simbólicas e materiais particulares. Noutras palavras, "[...] mais do que pensar nas artes como fazendo alguma coisa para as pessoas, deveríamos pensá-las como coisas que as pessoas fazem" (GAZTAMBIDE-FERNÁNDEZ, 2013, p. 226, grifo do autor). Em relação aos contextos educacionais, deveríamos pensá-las como situações nas quais os estudantes - cujas vidas já se encontram imbuídas de "criatividade simbólica", envolva isso alguma coisa chamada "artes" ou não (GAZTAMBIDE-FERNÁNDEZ, 2013, p. 227) - pudessem engajar seus próprios repertórios, reelaborando as representações que fazem de si mesmos e do mundo, sem necessariamente reiterar a circulação de representações dominantes.

\section{Algumas considerações}

Resta saber se tal "argumento" seria convincente. Por certo, ele não cancela a demanda por argumentos. De que forma então se reportaria à divisão entre argumentos essencialistas e contextualistas? A princípio, a filiação de GaztambideFernández aos Estudos Culturais - particularmente ao trabalho de Paul Willis (1993) _, na medida em que parece centrada nas necessidades dos estudantes, deveria 
inscrevê-lo numa abordagem contextualista. Porém, ironicamente, essa é a abordagem mais condizente à retórica dos efeitos. Por outro lado, referir-se às artes como um "constructo discursivo" sugere que elas não teriam nenhuma essência a reivindicar; que suas "qualidades intrínsecas" estariam desde sempre atravessadas por suas exterioridades.

Em suma, talvez pudéssemos superar a dicotomia daquele esquema argumentativo - que tende a separar desejo (interno) e demanda (externa) -, propondo que o intrínseco se revertesse no instrumental e vice-versa. Talvez esse movimento (algo dialético) pudesse, ele sim, justificar-se "em si mesmo". Ao menos enquanto tática, no sentido de rejeitar a moldura imposta pelo governo ao debate educacional, que por vezes reinstala uma dimensão paranoica da autolegitimação, da qual seria preciso escapar. Parte disso, por certo, implicaria relativizar nossa própria importância (autorreferida, institucionalizada), para então assumir outra importância, assim como outras práticas, abertamente políticas e sociais.

Em todo caso, a situação das artes é certamente diferente daquela da ciência. Para se justificar socialmente, basta que o discurso científico seja justificado pela comunidade (ou instituição) científica. Por sua vez, as artes (assim como o ensino das artes) precisam se justificar diante de exigências "científicas", que naturalmente não Ihes equivalem em competência, mas que na verdade já não podem justificar-se em si mesmas (LYOTARD, 2000). De qualquer forma, não basta às artes manifestar seus compromissos éticos e estéticos, mesmo no que diz respeito ao trabalho com as emoções e os afetos, ao reconhecimento das diferenças, à construção do saber viver, fazer, escutar etc. - eis que tais compromissos deixaram de ser consensuais.

\section{Referências}

BARBOSA, Ana Mae. Teoria e prática da educação artística. São Paulo: Cultrix, 1975.

BARBOSA, Ana Mae. Arte-educação: conflitos/acertos. São Paulo: Max Limonad, 1984.

BARBOSA, Ana Mae. (Org.). Inquietações e mudanças no ensino da arte. São Paulo: Cortez, 2002.

BARBOSA, Ana Mae. A imagem no ensino da arte. 5. ed. São Paulo: Perspectiva, 2004.

BARBOSA, Ana Mae. (Org.). Ensino da arte: memória e história. São Paulo: Perspectiva, 2008.

BARBOSA, Ana Mae. A importância do ensino das artes na escola; entrevista a Beatriz Morrone. Revista Época, 16 mai. 16 [2016a]. Disponível em <https://glo.bo/1R6KoBx>. Acesso em 27 jun. 2018. 
BARBOSA, Ana Mae. Era uma vez... A obrigatoriedade das artes no currículo do ensino médio. Revista Select, n. 33, 13 dez. 16 [2016b]. Disponível em <http://bit.ly/2wEyHnD>. Acesso em 30 jun. 2018.

BARROCAL, André. "Doutrina do choque" explica Brasil de Michel Temer. Revista Carta Capital, 26 ago. 2017. Disponível em <https://bit.ly/2IEPoB1>. Acesso em 30 jun. 2018.

BRASIL. Parâmetros Curriculares Nacionais. Brasília: MEC, 1997.

FAEB. Nota pública da FAEB sobre a Medida Provisória do Ensino Médio. 23 set. 2016. Disponível em $<$ http://bit.ly/2vbpQta>. Acesso em 27 jun. 2018.

FAEB. Carta de Campo Grande sobre as mudanças no Ensino Médio para o ensino de arte. 18 nov. 2017. Disponível em <http://bit.ly/2AMNTAO>. Acesso em 27 jun. 2018.

FAVARETTO, Celso. Moderno, pós-moderno, contemporâneo: na educação e na arte. São Paulo: USP, 2004. Tese de Livre-Docência.

FCG. Nota de Repúdio do VI Encontro do Fórum de Coordenadores dos Cursos de Graduação em Artes Visuais. 26 set. 2016. Disponível em <https://bit.ly/2KrFFjg>. Acesso em 27 jun. 2018.

GAZTAMBIDE-FERNÁNDEZ, Rubén. Why the Arts Don't do Anything: Toward a New Vision for Cultural Production in Education. Harvard Educational Review, v. 83, n. 1, pp. 660-685, Spring 2013. Disponível em: <http://bit.ly/2jQEtNa>. Acesso em 08 jul. 2018.

LANGER, Susanne K. The Cultural Importance of the Arts. The Journal of Aesthetic Education, Vol. 1, No. 1 (Spring, 1966), pp. 5-12. Disponível em <https://bit.ly/2ILFqOj>. Acesso em 02 jul. 2018.

LYOTARD, Jean-François. A condição pós-moderna. São Paulo: José Olympio, 2000.

WILLIS, Paul. Common culture - symbolic work at play in the everyday cultures of the young. Boulder; San Franscisco: Westview Press, 1993.

\section{Cayo Honorato}

É Professor Adjunto no Departamento de Artes Visuais (VIS) do Instituto de Artes (IdA) da Universidade de Brasília (UnB), na área de História e Teoria da Educação em Artes Visuais; orientador de mestrado credenciado no Programa de Pós-graduação em Arte da UnB. Doutor em Educação pela Faculdade de Educação (FE) da Universidade de São Paulo (USP), na linha de Filosofia e Educação, com estágio na Faculdade de Filosofia e Letras da Universidade de Granada (UGR), Espanha; mestre em Educação pela Faculdade de Educação (FE) da Universidade Federal de Goiás (UFG), na linha de Cultura e Processos Educacionais; especialista em Arte Contemporânea e bacharel em Artes Visuais pela Faculdade de Artes Visuais (FAV) da UFG. É vice-líder do grupo Mediação em Arte e Cultura: Teorias e Práticas, cadastrado no CNPq. Integra a rede Another Roadmap for Arts Education desde 2015. É pesquisador associado do Centre for the Study of the Networked Image (CSNI) da London South Bank University (LSBU), Reino Unido, desde 2018.

E-mail: cayohonorato.unb@gmail.com

Currículo: http://lattes.cnpq.br/8539725380344782

Recebido em 23 de agosto de 2018 Aceito em 12 de novembro de 2018 